\title{
A Narratividade do discurso jornalístico - a questão do outro
}

\section{Fernando Resende}

\section{Resumo:}

Este artigo faz uma análise comparativa da escritura fílmica de dois documentários, Falcão - os meninos do tráfico e Notícias de uma guerra particular, que, considerados de cunho jornalístico, devem nos auxiliar a refletir acerca da representação do Outro, levando em conta algumas das amarras epistemológicas que, de uma perspectiva hegemônica, têm orientado a reflexão sobre o campo do Jornalismo. Considerando tanto o avanço tecnológico que propicia e exacerba a produção dos discursos midiáticos como a noção de um poder, de caráter libidinal (Castro-Gómez), que se instala nas sociedades globalizadas, este artigo problematiza a produção dos discursos jornalísticos, provocando uma reflexão em torno do que os Estudos Culturais hoje enfrenta como desafio: lançar-se a uma teoria crítica da sociedade contemporânea. Cientes da polarização e da pulverização das falas na atualidade, acompanhamos Foucault e, à luz do pensamento de Flusser sobre as imagens técnicas e suas informações indicativas, sugerimos que, na perspectiva do discurso jornalístico, é fundamental compreender os modos de encenação das notícias.

\section{Palavras Chave:}

jornalismo, linguagem, cultura, representação

\begin{abstract}
:
This paper proposes a comparative analysis of the filmic scriptures in two documentaries: Falcão - os meninos do tráfico e Notícias de uma guerra particular. Considered as journalistic undertakes, these films might help the reflections on the representations of the Other, dealing with epistemological limitations which, from an hegemoniacal point of view, has oriented the studies about the field of Journalism. Considering both technological advances, which improves the productions of media discourses, and the notion of a libidinal power (Castro-Gómez), which settles down in global areas, this paper looks on the production of journalistic discourses by reflecting the current challenge of Cultural Studies: to throw light on a critical theory about contemporary society. Aware of the polarization and the shattering of nowadays speeches, we observe Foucault's formulations. Besides, we consider Flusser's thought on technical images and their indicative informations to suggest that, in the perspectives of journalistic discourse, it becomes fundamental to understand the way media reports install their own performances.
\end{abstract}

\section{Keywords:}

journalism language, culture, representation

Nos dias atuais, ao considerarmos a relevância do avanço tecnológico no processo de recrudescimento da produção dos discursos midiáticos, a questão da representação das diferenças apresenta-se como um tema central. Diante da diversidade de meios através dos quais se pode narrar os acontecimentos, a comunicação social, e em particular o jornalismo, assume um papel preponderante: ele é um lugar a mais de onde se tece a vida do outro. O Jornal Folha de S. Paulo do dia 26 de março de 2006 traz vários artigos 
sobre os produtos da mídia que têm como temática os dilemas da favela no Brasil. São variados os produtos midiáticos cujo conteúdo gira em torno deste problema, e a apresentação de um documentário, Falcão - os meninos do tráfico, além de reacender a discussão em torno do tema que aborda, nos auxilia a conduzir esta reflexão.

Exibido e exaustivamente anunciado pelo "Fantástico" no dia 19 de março de 2006, o documentário foi feito pelo Rapper MV Bill, que, nas suas entrevistas se auto-intitula mais legítimo para falar daquele lugar, pois é alguém que nasceu e viveu nas favelas. Ao apresentar o que ele considera ser a realidade dos menores que servem de "vigias" dos morros, MV Bill, através das imagens que produz, acredita ser capaz de mobilizar o país de forma distinta. E a TV Globo, que então anuncia uma interrupção de 1 hora em sua programação dominical, parece compactuar com a certeza de MV Bill, pois afirma que teremos acesso, naquele domingo, a imagens nunca antes vistas sobre o tráfico e as favelas.

De fato, as imagens causam um tremendo impacto. No dia seguinte, as falas dos que assistiram ao documentário trazem, basicamente, dois enfoques: enquanto alguns se mostram absolutamente chocados com o que viram, outros assumem uma postura de indiferença, pois se dizem já sabedores daquele fato: eles são bombardeados diariamente com notícias e imagens sobre o mesmo tema. A reação do primeiro grupo parece nos apontar de que forma o pânico que eles sentem encontra sua materialização nas imagens de meninos que, com as faces cobertas por uma tarja preta, revelam a dureza e a crueldade de se viver do tráfico. O outro grupo, por sua vez, parece nos dizer que não há nada de novo naquelas imagens, pois aquilo de que elas dizem é algo já visto e mostrado em vários outros lugares. O exemplo do impacto causado pela apresentação daquele documentário no cenário televisivo revela-nos o que também não é novo: impotentes diante de uma realidade tão distante do que somos ou desejamos, ficamos sempre fadados ao pânico ou à indiferença.

Para a antropóloga Alba Zaluar, a repercussão de Falcão - os meninos do tráfico deixa "provado mais uma vez o poder de comunicação que o veículo televisão tem sobre os demais, não só pela sua capacidade de penetrar em tantos lares, mas pela força das imagens, associadas à voz e à letra do que é dito" (Folha de S. Paulo, 26/03/2006). O episódio, ao que parece, traz à tona a força das imagens técnicas que, além de nos levar a buscar os fatos naquilo que eles revelam de mais verdadeiro, fazem, por exemplo, com que o realizador, por razões ligadas à sua própria experiência de vida, se apresente como detentor de uma fala legítima. Assim, fazendo-nos presos "à voz e à letra do que é dito", nós nos atemos sempre ao objeto da fala - ao tema propriamente dito -, enquanto nos perdemos cada vez mais dos modos de encenar as notícias, da fala que está contida no objeto.

Atentos, por exemplo, à fala de outro documentário, Notícias de uma guerra particular - também de cunho jornalístico e cuja proposta é representar modos de vida e personagens relacionados ao tráfico nas favelas brasileiras -, percebemos que uma das estratégias narrativas que o marca é a visada panorâmica que temos da cidade do Rio de Janeiro, um espaço urbano que inclui, nas suas contradições, a favela e o asfalto. Em vários momentos no decorrer da tessitura dessa narrativa, somos levados, pela câmera, a ver de cima um emaranhado de luzes, casas, prédios, carros e traçados de ruas que, na nossa perspectiva, anuncia a diversidade de vidas e trajetórias que há por conhecer. A imagem que vemos é a mesma sobre a qual reflete Michel de Certeau (2000) ao discutir as questões sobre a cidade e os seus caminhantes: vistas de cima, segundo o autor, compreendemos estar no traçado feito pelos seus pedestres a dimensão complexa que habita as nossas cidades; ou seja, toda cidade somente se desenha na medida em que o caminhante nela traça o seu caminho.

Em Notícias..., essa paisagem que se abre para nós é logo entrecortada por outras que nos revelam os labirintos da favela, nos deixando ver rostos e lugares plenos das contradições e dos paradoxos que desenham o espaço urbano no qual vivemos. Essa visão do micro não é alheia ao macro que o circunda, 
pois o que vemos por entre os labirintos - crianças brincando, armas e drogas nas mãos dos traficantes, ruas sujas por onde transitam os pedestres - lhe é constitutivo. Logo sabemos que as notícias às quais teremos acesso são sim de uma guerra particular, mas um particular que nos acomete a todos.

Para além dos possíveis efeitos causados pela apresentação desses documentários, este artigo, ao comparar as tessituras narrativas de Falcão... e Notícias..., entende que, para o jornalismo, no momento atual, é fundamental um olhar que busque conhecer os modos de narrar os fatos. Acreditamos, pois, que é no processo de construção narrativa - nos modos de encenação das notícias - que podemos revelar e avaliar alguns dos mecanismos de produção das diferenças, o que, de acordo com Castro-Gómez (s/d), é um dos desafios da teoria crítica nas sociedades contemporâneas. Sob essa perspectiva, tomamos como referência algumas das estratégias que têm legitimado o discurso jornalístico no Brasil, com o objetivo não só de discutir a problemática de um discurso que raramente enfrenta o desafio de um diálogo com o outro, mas também de refletir acerca da produção de conhecimento sobre esse mesmo discurso.

\section{O Eu e o Outro na dinâmica da representação}

Os estudos do jornalismo no Brasil, que nos últimos anos concentraram suas interrogantes na perspectiva do conteúdo, do que comportava e significava a notícia, por exemplo, traziam como questão de fundo o desejo de conhecer e explicar o conceito de jornalismo. Uma abordagem absolutamente necessária, tendo em vista o lugar inaugural de um campo que se constituía, muito mais, a partir de uma prática - de um fazer desprovido de reflexão - do que de uma práxis. Esta prática, essencial e urgente quando a razão iluminista buscava encontrar lugares por onde extravasar o seu desejo de esclarecer e explicar os fatos do mundo, ao se deixar instaurar como um campo de conhecimento revestiu-se de uma necessidade de explicar-se a si mesmo, fato que se deu à luz do que se concebe como sua matéria-prima, a informação, e da função que lhe era atribuída: mostrar à sociedade o que nela é o acontecido.

Assim, haveríamos de entender o que é jornalismo não da perspectiva do que este campo traz como ordem complexa, mas a partir de propostas assépticas que, no campo da comunicação como um todo, tomava qualquer ruído como indesejável, porque tornaria sua prática menos cumpridora dos seus deveres que, resumidamente, no caso do jornalismo, seriam mostrar, esclarecer e explicar os fatos do cotidiano. No bojo desses estudos (1), procuramos respostas para o que é jornalismo, discutindo questões de ordem ética - qual deve ser a postura e o papel do jornalista, por exemplo -, e a relevância deste que se legitimava como o lugar em que os fatos seriam revelados, como se, no próprio ato de trazer os fatos à tona, não estivesse contida toda a complexidade da qual se procurava escapar.

Sob essa ótica, também porque a este campo é dado tratar do imediato, nossos estudos e práticas se dedicaram a criar formas que nos possibilitam falar do micro, utilizando a objetividade como ritual estratégico (Tuchman, 1999) e separando os relatos em gêneros - informativos e opinativos, por exemplo -, de modo a nos livrarmos das possíveis incoerências presentes em qualquer ordem discursiva. Há de se compreender que, nos tempos atuais, quando as próprias máquinas nos permitem o uso de inúmeras formas de narrar o cotidiano - o que diz das nossas guerras particulares -, esse modo de falar, então legitimado pelo discurso sobre o jornalismo, está distante de enfrentar um desafio que nos parece central: lançar-se ao encontro do outro. E, nesse sentido, a tessitura narrativa que encontramos em Falcão... é elucidativa.

$\mathrm{Na}$ abertura deste documentário, logo percebemos que o tema será tratado de um ponto de vista reducionista, seja porque o veremos à luz da opinião daquele que o recorta - MV Bill, o seu autor -, seja porque o fato será tomado como se ele não fizesse parte de uma espacialidade que o complexifica. Com Falcão..., entramos em uma favela enquadrada pela janela de um carro, onde também está MV Bill, quem nos fala e nos explica o que é aquele lugar. Não entramos ali para descobrir o que se esconde nos 
labirintos da cidade, mas para saber o que é a vida na favela. O tom didático-explicativo, presente no discurso do autor e nos vários depoimentos que virão a seguir, ainda que seja coerente com os propósitos do realizador do documentário - já que ele diz saber o que mostrar -, é revelador, antes de tudo, da problemática relação que há entre o eu e o outro na perspectiva da representação.

Um dos dilemas éticos que atravessa não só a produção de documentários, mas todos os objetos que, no viés da representação, se incubem da função de falar do outro, diz respeito aos modos de representar este outro na sua diferença (2). Assim, se nos é caro pensar como tornar possível que o outro seja visto para além do que os nossos olhos reconhecem como "familiar", parece-nos também fundamental entender que à luz de uma escritura, fílmica ou de qualquer outra ordem discursiva, o olhar que se reduz a uma dimensão didática e/ou opinativa - a mesma que inscreve o jornalismo em uma epistemologia iluminista e condutista (Resende, 2002) - é insuficiente. Em se tratando de Falcão..., por exemplo, através do que nos é dado a ver, o que ressalta é a total falta de perspectiva e de possibilidade de relação: diante da incoerência do que vejo, torno-me absolutamente impotente. Para Amir Labaki, crítico de jornal, "os entrevistados [em Falcão...] são despersonalizados por tarjas nos olhos ou esfumaçamentos no rosto, sem identidade exceto a associação com o crime e a violência". E o espectador, dirá Labaki, "assistiu a uma esticada reportagem sensacionalista, sem nenhuma novidade factual" (3).

\section{Jornalismo: enunciação e vontade de verdade}

O campo dos media vive um processo de correlação de forças com vários campos sociais - políticos, econômicos, culturais, religiosos, entre outros - já que ele se faz estrutural na constituição e na composição desses lugares. Tendo em vista o fato de que ao jornalismo, mais especificamente, cabe a tarefa de dizer sobre e para as demais instâncias sociais, havemos de considerar que um dos lugares possíveis em que se instala a correlação de forças, com todas as suas assimetrias e fragmentações, é o campo do discurso. Instância fundamental para se pensar a questão da representação quando, no momento atual, as noções alteradas de espaço e tempo reconfiguram os papéis e as pertinências tanto dos campos como dos atores sociais que constituem a sociedade e com os quais os produtos midiáticos, invariavelmente, dialogam (Resende, 2003).

Sob essa ótica, a problemática da representação das diferenças, na perspectiva dos produtos jornalísticos, estabelece uma intrínseca relação com a questão da enunciação. Para Benveniste (1995), o sujeito da linguagem está no centro da reflexão, é o locutor em sua relação com o destinatário, o "eu" em sua relação com o "tu"; o autor parte da distinção entre o enunciado, já concretizado, e a enunciação, a ação de produzir o enunciado. Benveniste concentra-se na forma pela qual o sujeito se marca naquilo que diz, estabelecendo, assim, o que se convencionou chamar de "Teoria da Enunciação". O autor afirma: "A linguagem só é possível porque cada locutor se apresenta como sujeito, remetendo a ele mesmo como eu no seu discurso. (...) A polaridade das pessoas é na linguagem a condição fundamental" (Benveniste, 1995: 286-7). Nessa mesma perspectiva teórica, ainda que em uma direção distinta, Bakhtin (1979) mostra que a enunciação é um fenômeno social e não individual, estando determinada por um contexto histórico que acaba por conformar a própria subjetividade; um outro dado que nos parece relevante em se tratando da reflexão em torno da enunciação jornalística.

A referência a Foucault (1996) também nos parece fundamental, quando entendemos que o gesto de proferir um discurso implica o que este autor chama de "vontade de verdade". Ao trabalhar com os três procedimentos de exclusão nos quais opera a produção do discurso (a interdição, a segregação e a vontade de verdade), Foucault explicita os modos de legitimação do lugar do sujeito falante, calcando estes modos nas condições sociais em que se operam e se proferem os discursos.

Tomando o terceiro procedimento - a vontade de verdade - como centralizador, porque, ao mesmo tempo 
em que reformula, legitima os outros dois, o autor nos auxilia a pensar no campo dos media, e, portanto nos seus lugares de fala, como legitimador da nossa vontade de verdade. Se, para Foucault, as sociedades do saber eram outrora as instâncias legitimadoras de uma fala que se pretendia verdadeira, podemos supor que hoje a mídia, com o seu amparo institucional e através dos seus objetos que produzem falas, constituise como uma instância fundamental, porque certamente reguladora e mantenedora de um status quo que visa à ordenação dos fatos que tecem nossas relações sociais.

Trata-se de pensar que é dada ao campo do jornalismo a tarefa de produzir saber acerca dos acontecimentos do mundo, tarefa que lhe é outorgada tanto porque detém a tecnologia - uma força maquínica incomensurável - como também porque outras instituições produtoras de saber - de caráter pedagógico - conferem aos que proferem os discursos da mídia o direito da fala. A partir desses lugares, pelo desejo e pelo poder, revestidos da vontade de verdade, os discursos jornalísticos tornam-se expressões máximas do que é verdadeiro; e é com eles, vale dizer, que construímos os nossos modos de compreender e ver o mundo, visões que tecem nossa percepção do outro e nossa maneira de lidar com o diferente ou o semelhante.

Foucault nos alerta também para o fato de que o procedimento da segregação, ainda que esteja cada vez mais enfraquecido, não sofre necessariamente uma ruptura, pois, diz o autor, “(...) é sempre na manutenção da censura que a escuta se exerce" (1996: 13). Ou seja, no campo dos media, essa condição se confirma: o outro, quando fala, fala sempre de um deslugar, porque invariavelmente fala através daqueles que lhes concedem este direito, uma condição antes de autoridade, muito distante do que se espera de um exercício de alteridade. E é este procedimento, cumpre fazer notar, que reitera aquele primeiro, o da interdição, o indicador de que "não se tem o direito de dizer tudo, que não se pode falar de tudo em qualquer circunstância, que qualquer um, enfim, não pode falar de qualquer coisa" (Foucault, 1996: 09).

Assim, configura-se um círculo vicioso no campo dos media e é corroborada a idéia de que a verdade está antes no que o discurso diz, no seu enunciado, nunca, porém no que ele faz ou mesmo no que ele é. Nesse aspecto, o jornalismo, ainda que não de forma exclusiva, é exemplar na reiteração deste pressuposto: quem fala e de onde fala são critérios absolutamente relevantes e definidores do que é ou deixa de ser verdade. Cremos ou fingimos crer na idéia de que a verdade ali está, seja porque o lugar de representação do acontecimento é institucionalmente legitimado ou porque aquele que profere o discurso, na figura empírica do sujeito que fala, tem credibilidade; ainda que às vezes possamos dele duvidar, vale dizer, por razões quase sempre de natureza ideológica. Nesse sentido, acompanhando a reflexão de Foucault, questionar e problematizar a vontade de verdade parece essencial.

\section{Polarização e pulverização das falas}

A título de exemplo, lembremo-nos da seguinte situação: à época da invasão sofrida pelo Iraque, no ano de 2003, vários jornais - impressos, televisivos e outros - noticiavam o acontecimento ora da perspectiva dos invasores ora, diziam os objetos da mídia, da perspectiva dos invadidos. Os embedded journalists, acoplados aos tanques de guerra para que pudessem narrar o fato com maior fidelidade, acabaram por revelar quão frágeis são os discursos que sobrevivem de informações indicativas, estes que se apóiam na vontade de verdade como o seu condicionante primeiro (4). Um olhar mais atento aos relatos da CNN empresa de mídia estadunidense que na época vendia e propagava para o mundo as notícias oficiais sobre o que chamavam de "guerra contra o mal" -, nos faz perceber que os dizeres eram, com exclusividade, aquilo que o país invasor nos queriam fazer crer. A entrada em cena da Al Jazeera - rede televisiva de origem árabe que se dizia mais apta a contemplar e relatar os fatos da perspectiva dos invadidos -, indubitavelmente um marco no cenário da mídia contemporânea, polarizou os discursos: se a guerra era 
contra o mal, o mal agora se dispunha a falar.

Este processo de polarização das falas, um exemplo dos modos de manifestação do conflito no espaço da mídia, não traz como novidade o fato de que cada um, do seu lado, tenha algo a dizer, este aspecto já é sabido desde que o homem busca formas de se expressar. O novo vem particularmente do fato de que as falas polarizadas fazem saltar aos olhos uma situação que é específica do contemporâneo e que tem absoluta relação com o próprio avanço tecnológico: os relatos nos chegam com mais velocidade, de todos os lados, por vários meios e de diversas formas. Muito provavelmente, nunca antes no Ocidente - pelo menos da perspectiva do Brasil - notou-se uma presença tão significativa de uma mídia nascida do lado de lá. Ou seja, a Al Jazeera invade, com sua força local e no mesmo tempo real das outras redes, o espaço midiático antes mais facilmente dominado pelos Estados Unidos.

Sua chegada, com tamanha força e rapidez, faz com que nos defrontemos com o fato de que cada discurso a seu modo, em concomitância, quer ser apresentar mais verdadeiro que o outro. Ambas as falas ancoramse, com veemência, na suposta legitimidade tanto do sujeito falante como do lugar de onde se fala. E desse modo, a simultaneidade de exposição desses dizeres, que nos chegam através dos discursos da mídia, é fundamental para entendermos que o embate alcança o seu extremo, reduzindo o discurso à sua vontade de verdade, procedimento que se exacerba a partir da luta pela ocupação do espaço midiático.

Não bastasse essa polarização, os relatos nos chegam de vários lugares e de formas diversas: weblogs noticiosos e de cunho pessoal, de habitantes do país invadido ou do país invasor, que relatam os fatos na perspectiva que lhes convém; filmes, documentários e programas de TV a cabo, que buscam narrar os fatos de formas distintas das que nos chegam pela mídia oficial; outros meios impressos, inclusive livros, que revelam histórias não contadas nos grandes jornais; textos, muitas vezes encontrados na chamada "grande imprensa" que, em situações extremas, abrem espaço para formas variadas de relatar o cotidiano. Assim, essa fala pulverizada e polarizada, por explicitar e tornar evidente a vontade de verdade como marca do discurso midiático, nos impele à indagação acerca da própria verdade, fazendo-nos duvidar das legitimidades dos lugares e dos sujeitos falantes que se impõem nos dizeres da mídia. Ademais, é sob essa perspectiva que problematizamos a questão das diferenças no âmbito destas narrativas.

Ao discutirem "o desafio de ir ao encontro do outro" na escritura dos documentários, Guimarães \& Lima (2007: 154) sugerem que um dos gestos fundamentais a serem compreendidos diz respeito à necessidade de "abandonar o Eu como medida para conhecimento do Outro". É preciso "descentrá-lo radicalmente, conceder ao Outro a prioridade que até então era concedida ao Eu". Sob essa ótica, MV Bill, quando se auto-intitula legítimo para falar da favela, fazendo-nos conhecê-la através de uma tessitura narrativa que reflete os seus olhos, ativa um gesto revelador: o que ali se apresenta é a vontade de verdade do seu discurso, o que inviabiliza, no contexto da representação, qualquer encontro com o outro.

No caso específico dessa narrativa, sua fala em primeira pessoa não se revela um problema tão-somente porque se faz na perspectiva de um Eu, mas também porque a ela acoplam-se outras falas que buscam explicar, num tom enciclopédico, o que é o tráfico - esmiuçando verbetes, como o que é o fogueteiro e o que é o crack, por exemplo - dando-nos informações indicativas que são, por sua vez, associadas a imagens que nos dizem como ver os personagens. E mais, através da câmera de Falcão..., os meninos do tráfico ora são vistos de baixo para cima, ora de cima para baixo, a câmera raramente se coloca no nível dos meninos, a menos que com o objetivo de mostrar os seus olhos vendados ou os seus corpos esfumaçados. Desse modo, a perspectiva se mostra meramente conteudística, é como se os relatos que ouvimos e as cenas que assistimos não fizessem parte da escritura; eles foram ali enquadrados e, antes, descrevem, mas não escrevem o acontecimento.

Nesse sentido, a escritura fílmica de Falcão... é especular em relação ao cenário midiático que aqui 
buscamos compreender: os vários Eus, que, na explicitude da vontade de verdade do discurso, inviabilizam o diálogo, reverberam, a partir do micro-espaço da narrativa, uma situação mais ampla: são várias vozes, ou uma cacofonia se assim quisermos pensar; o avesso da dimensão polifônica (Bakhtin) minimamente necessária para aventarmos a hipótese de um exercício de alteridade. Do ponto de vista da reflexão acerca dos discursos jornalísticos, que tanto se ancoram no pressuposto de que ali esteja contida uma verdade, a situação social e tecnológica do contemporâneo renova nossas condições de reflexão: o que a polarização e a pulverização das falas de fato nos revelam - no macroespaço midiático e na tessitura de muitas de suas narrativas - é que se tudo é vontade de verdade, a verdade, ou mesmo a nãoverdade, pode estar em vários lugares e em várias falas.

\section{Velamento e produção das diferenças}

Há ainda uma agravante: o avanço tecnológico que experimentamos com extrema força e velocidade no século XX nos colocou antes a serviço das máquinas. Envoltos em um imaginário secular que tem como princípio o progresso e o ordenamento do mundo, vivemos em busca de fórmulas facilitadoras que nos ajudem a apreender o mundo de forma simples; queremos tê-lo explicado, muito mais que problematizado. E, nesse sentido, a tecnologia - particularmente com os seus aparelhos produtores de imagens - cumpre um papel central. Vilém Flusser chama atenção para o fato de que as imagens técnicas interpõem-se entre o homem e o mundo, funcionando, na verdade, como biombos. Para este autor, "o homem, ao invés de se servir das imagens em função do mundo, passa a viver em função das imagens. Não mais decifra as cenas da imagem como significados do mundo, mas o próprio mundo vai sendo vivenciado como conjunto de cenas" (2002: 09). Tal observação põe em questão o fato de que as imagens produzidas pelas máquinas têm cumprido, de certa forma, a função de nos explicar o mundo, servindo como objetos facilitadores; quando vemos o que é "dito" pelas imagens, acreditamos ter ali o mundo fielmente representado (5).

Sob essa ótica, mais uma vez, o documentário Falcão... é exemplar: o conjunto de vozes e imagens que pretendem nos explicar os dilemas do tráfico, além de vir ao encontro do nosso "analfabetismo", diria Flusser, recorta e reparte a vida na favela, impedindo-nos de exercitar o gesto do compartilhamento. O que vemos e ouvimos são cenas que, somente no seu desejo de transparência, oferecem respostas para os nossos dilemas, tal qual o é, muitas vezes, o discurso jornalístico que, à luz de uma mesma ordem explicativa, se baseia prioritariamente em estatísticas e números. Não se trata de pensar toda a produção jornalística sob essa perspectiva, mas, em linhas gerais, no quadro epistemológico dominante neste campo, seus números de mortos, suas definições generalizadas, seus rótulos que simplificam problemas antes de tudo complexos muito contribuem para a concepção de um mundo que parece passível de ser ordenado e, no entanto, impossível de ser compartilhado.

Os textos e as imagens produzidos sob o jugo desta episteme encontram sua motivação e razão de ser no ideal de que neles, quanto mais pura e exata for a informação, mais próximos da comunicação estarão os seus relatos. Trata-se na verdade de uma dimensão antes quantitativa, não há indagação em torno da qualidade da informação, mas do volume de informação (novidade) contida no relato e do quão rápido ela chega ao seu consumidor. Estes objetos da mídia são produzidos com o intuito de chegarem o mais próximo possível do real da coisa representada, seguros de que, desse modo, falarão a verdade, pressuposto primeiro da vontade de verdade que está neles instalada. E este aspecto explica ainda o fato de que neles a perspectiva de que há um outro para quem se fala é praticamente anulada. Flusser, ao refletir em torno do aparelho fotográfico, diz que ele "é programado para distribuição discursiva rumo ao espaço vazio, como o fazem a televisão e o rádio" (2002: 46), no que, certamente, acrescentaríamos os jornais. Um "espaço vazio" ocupado por um grupo disforme para o qual e sobre o qual falam os produtos da mídia, lugar onde todas as diferenças são veladas como se fossem mortas e, ao mesmo tempo, como se 
pudessem ser apagadas.

Este processo de velamento das diferenças, considerando as idiossincrasias históricas, sociais e culturais dos dias atuais, convive com um outro, também provocado pela polarização e pela pulverização dos lugares e das falas: o processo de produção das diferenças. Quando se narra o cotidiano das favelas, por exemplo, da perspectiva de vozes e lugares tão diferenciados, somos chamados a atentar para o fato de que as categorias definidas para explicar as lógicas que dominam a formatação dos textos e das imagens técnicas precisam se fazer mais fluidas, sob o risco de não podermos jamais falar com o outro. Neste caso, particularmente, vale atentar para o que dizem Guimarães \& Lima (2007: 149) em relação às dificuldades de ir ao encontro do outro no âmbito da representação: "[elas] aumentam sobremaneira quando se trata de filmar o outro de classe, pertencente a um grupo social à margem (...) da esfera de visibilidade”.

Assim, emoldurar vozes e cenas que se propagam à revelia do outro é mero estímulo de produção de diferenças, pois é importante lembrarmos que continua em jogo a busca pela verdade (Foucault, 1996). Ou seja, quem fala através dos meios continua sendo aquele que se pensa mais legítimo para falar e o que ocorre, nesses casos, é uma alternância de papéis, ou de poderes no espaço midiático, pois quem fala é sempre um eu que deslegitima um outro. Assim, entendemos, a diferença que se produz neste discurso é puro efeito, tal qual o é a verdade de que ele se vale. Nesse contexto, parece importante notar que o processo de produção das diferenças, que não resulta em relação de alteridade, é simplesmente parte de uma lógica do capitalismo tardio - quando as máquinas de produção de informação e conhecimento ganham primazia. E é portanto nesse quadro que, além de ser importante saber o que o discurso diz, é fundamental investigar o que ele faz.

\section{A encenação da notícia: o poder libidinal}

Trata-se de uma perspectiva desafiadora e é no viés da cultura que nos parece possível reconhecer a dimensão complexa que inscreve os discursos midiáticos como instâncias produtoras de sentido. Os Estudos Culturais representam um esforço de condução do pensamento em direções mais afeitas ao cotidiano e à cultura. Porém, para não corrermos o risco de nos prendermos a um viés culturalista, que negligenciaria a relação da cultura com a economia política, é preciso redimensionar o papel da teoria crítica da cultura à luz da lógica do capitalismo tardio e do papel dos meios de comunicação na sociedade contemporânea. Para Santiago de Castro-Gómez (s/d: 03), "o ponto de largada dos Estudos Culturais são (...) os dispositivos a partir dos quais os bens simbólicos (a cultura) são produzidos e oferecidos ao público como mercadoria".

Este aspecto faz com que nossas atenções sejam redobradas, pois com ele abarcamos a idéia de que as imagens e os textos que produzimos, inclusive no jornalismo, são representações plenas de ideologia e cultura (6). E nesse sentido, de acordo com Castro-Gómez, os meios são aparelhos ideológicos que carregam uma vantagem sobre os demais, pois "seus dispositivos de sujeição são muito menos coercitivos". Segundo o autor, "neles não circula um poder que 'vigia e castiga', mas um poder que seduz". Nesse aspecto, para além do poder disciplinário da modernidade, criticado por Foucault, CastroGómez diz que estaríamos agora "à frente do poder libidinal da globalização" (s/d: 14). Considerando que hoje a leitura que fazemos dos produtos midiáticos depende muito do modo no qual a notícia é encenada, Castro-Gómez diz:

A guerra das imagens sobre a guerra será ganha por aquele grupo que, no intuito de imprimir sentido, melhor utilize o poder libidinal, ou seja, por aquele grupo que ponha em marcha todos os mecanismos sedutores da imagem para obter o consentimento não coercitivo dos consumidores (s/d:16). 
Assim, atentos aos dispositivos dos quais nos servimos para encenar as notícias, percebemos que na "guerra das imagens sobre o tráfico e/ou a favela", o olhar exclusivo de quem se diz conhecedor daquela realidade pode até se apresentar de forma sedutora, mas, no âmbito da representação das diferenças, acaba se configurando reduzido, pouco atento à polissemia na qual se inscreve a própria vida, na favela ou em qualquer outro lugar. Arriscamos ainda a sugerir que, sob a perspectiva dessas imagens que reduzem a realidade, a escrita conduzida à revelia do outro traz no libidinal o próprio coercitivo, pois são elas imagens que nos impõem uma ordem única. Em Falcão..., ainda que nos seja anunciado que conheceremos a realidade do tráfico à luz dos olhos de quem o vive, descobrimos que prevalece o olhar de quem recorta e produz as imagens que veremos.

Um segundo aspecto que Guimarães \& Lima (2007: 154) apontam como fundamental ao enfrentarmos o campo ético da representação do outro nos documentários diz respeito à necessidade de "promover a disjunção entre a imagem e a palavra e, ao assumir que falar não é ver, libertar a palavra tanto do visível quanto do invisível". Em Notícias de uma guerra particular, temos acesso a uma justaposição de imagens e depoimentos que não se completam, porque são contraditórios, mas que se interpenetram, porque tecem a teia complexa das vidas que circundam a favela e o tráfico. Às experiências que nos relatam os menores, o chefe de polícia, os soldados, as famílias envolvidas no tráfico e, ainda, a própria mídia que, numa dimensão metadiscursiva também se revela personagem, somam-se imagens de um cotidiano absolutamente comum - crianças brincando nas ruas e pessoas caminhando em direção às suas casas ou ao trabalho - e da própria "guerra", ou do próprio "movimento", como também chamam o tráfico. No exercício da tessitura dessa narrativa, não há contraposição entre o certo e o errado, ou o bem e o mal, mas uma escrita que a todo tempo parece duvidar tanto da fala como da imagem; naquela escritura não se fala, necessariamente, o que será dado a ver e não se mostra, exclusivamente, o que a fala diz.

Alba Zaluar corrobora a nossa visão, revelando algumas das incoerências do que é dito no documentário de MV Bill. "Sem apresentar dados novos", segundo ela, "Falcão... lança um olhar terno sobre os pequenos traficantes, mas submerge na cultura do gueto e ignora os demais atores sociais presentes em 'Notícias de uma Guerra Particular"'. Assim, ao comparar os dois produtos, ficamos sabendo que aquela notícia encenada daquele ângulo deixa à deriva outros ângulos que podem ser também significativos para a compreensão do problema. Em Notícias..., João Moreira Salles, que não traz em si a marca de quem viveu em uma favela, ao abordar o tema na perspectiva dos policiais e dos bandidos, mostra-nos que "são muitas as vozes, muitos os atores do drama", diz Zaluar.

Os diversos produtos sobre as favelas, sejam os vários weblogs, documentários, relatos impressos e filmes sobre as guerras particulares do dia-a-dia - as pequenas grandes guerras que hoje somos impelidos a experimentar - dizem, antes de tudo, que há vários modos de narrar o acontecimento. E desse modo, entendemos, quando a notícia vira uma mercadoria pós-industrial, não basta sabermos do que se passa nas favelas, mas também dos modos que sobre elas se falam, instâncias nas quais várias vozes e vários sentidos podem, por vezes, se revelar.

\section{O jornalismo e a mediatização das falas}

Ao jornalismo, que entendemos como lugar de confluência de vozes e produção de sentidos (Benetti, 2007), parece significativo, no contexto contemporâneo, compreender que informar, ou produzir imagens e textos nos discursos cujos procedimentos internos são pautados por uma classificação de informações, significa dar forma ideológica e cultural aos fatos pré-existentes. Uma constatação relevante, mas que precisa ser problematizada e contextualizada nas dimensões em que se inscreve o jornalístico. Flusser (2002:49), ao dizer do processo de classificação de informações, nos ajuda a estender este problema: "todo indicativo científico" - onde cabem perfeitamente as informações jornalísticas - "tem aspectos 
políticos e estéticos; todo imperativo político tem aspectos científicos e estéticos; todo gesto optativo (obra de arte) tem aspectos científicos e políticos".

Com a problemática assim ampliada, parece-nos importante ressaltar que é preciso reconhecer que o lugar político das falas jornalísticas não se desvincula do estético que nelas se instala e ao qual elas se submetem. A agravante de que nos dias atuais o poder coercitivo esteja vinculado a um poder libidinal - o gesto sedutor pode ser também excludente -, além de ser um forte indicador de que, na dimensão do conflito, a ampliação do espaço de fala não significa necessariamente democratização dos meios, mantém-nos reféns daqueles que sabem melhor produzir as imagens e os textos. Desse modo, trabalhar na perspectiva de uma possível diferenciação dos narrares, ao mesmo tempo em que nos faz pensar sobre o estatuto do jornalismo em tempos de mediatização extrema dos acontecimentos, ensina-nos, quem sabe, a produzir e apontar diferenças: há narrares que, no intuito de explicar os fatos, buscam verdades totalizantes? Há outros que visam a uma dimensão mais complexa?

De acordo com Michel de Certeau (2002), a alteridade não consiste em falar do outro no texto, mas naquilo que vimos a saber sobre o outro através do que a escrita diz sem querer dizer. MV Bill, além de realizador de Falcão - os meninos do tráfico, é um rapper, o que provavelmente fez com que a música de fundo, naquele documentário, seja o rap. Novamente, uma comparação com Notícias de uma guerra particular pode trazer luz à nossa questão: o rap também aparece, não como um fundo, mas como parte da própria escritura. Em uma das cenas a que assistimos, o depoimento de um dos traficantes é absolutamente vinculado ao rap, tanto pelo ritmo da sua fala como pelo próprio uso que este personagem faz das suas palavras. Assim, o acontecimento noticiado - a vida e o tráfico na favela - é imbricado de intertextos que nos ajudam a compreender a complexidade e a tessitura daquele fato.

Para Correia (s/d: 14), o encontro de um equilíbrio, ou "qualidade", como diz o autor, na linguagem praticada no campo jornalístico, pode estar "no regresso ao texto, na busca das marcas enunciativas". Sem dúvida, ainda que seja relevante indagarmo-nos se as guerras, do tráfico ou de outras naturezas, serão assuntos no jornal do dia, diante dos processos de velamento e produção das diferenças, não deixa de ser menos importante procurar conhecer as formas e os lugares em que se darão os dizeres sobre as guerras. $\mathrm{O}$ avanço tecnológico que exacerba a produção das narrativas e faz saltar aos olhos a pluralidade de modos de narrar os fatos do cotidiano deve, pois, fazer-nos atentos à perspectiva de que há narrativas que dotam o mundo de diferenças, enquanto há outras que não; de que há as que rechaçam as particularidades e ainda há as que as ressaltam; há as que dizem de um lugar em movimento e as que narram o mundo como algo estático.

Na dimensão da representação, tudo parece indicar que é no reconhecimento da diferença desses narrares que enfrentamos melhor o dilema de irmos ao encontro do outro. Nesses modos variados, quando o que é trazido à cena é a própria vontade de verdade, redescobri-la na sua dimensão estética pode contribuir para que nos façamos aflitos, não necessariamente porque queiramos seguir em busca do verdadeiro, mas, muito provavelmente, porque desejamos conhecer os vários ângulos do mesmo problema. Neste lugar, alteramos o foco, o que está em questão é a verdade do acontecimento e não a de quem dele diz.

\section{Bibliografia:}

APPADURAI, Arjun. Modernity at large - cultural dimensions of globalization. Minneapolis: Univ. of. Minnesota Press, 2003. 
BAKHTIN, Mikhail. Marxismo e filosofia da linguagem. São Paulo: Hucitec, 1979.

BENETTI, Marcia. "Análise do Discurso em Jornalismo: estudos de vozes e sentidos”. In: LAGO, C. \& BENETTI, M. (orgs.). Metodologia de Pesquisa em Jornalismo. Petrópolis: Vozes, 2007.

BENVENISTE, Émile. Problemas de Lingüística geral. 4.ed. Campinas: Pontes, 1995.

CASTRO-GÓMEZ, Santiago. "Althusser, los estúdios culturales y el concepto de ideologia", http://www.javeriana.edu.co/pensar/Alt.html (acesso junho/2006)

CERTEAU, M. A invenção do cotidiano. Petrópolis: Vozes, 2000.

. A escrita da história. Rio de Janeiro: Forense Universitária, 2002.

CORREIA, João Carlos. "Linguagem jornalística, estranheza e referência". http://www.bocc.ubi.pt/pag/correia-joao-linguagem-jornalistica-estranheza-referencia.pdf (acesso julho/2007)

FLUSSER Vilém. A filosofia da caixa preta - ensaios para uma futura filosofia da fotografia. Rio de Janeiro: Relume Dumará, 2002.

FOUCAULT, Michel. A ordem do discurso. São Paulo: Loyola, 1996.

GUIMARÃES, C. \& LIMA, C. "A ética do documentário: o Rosto e os outros". In: REVISTA Contracampo, Niterói, UFF (2007/2).

RESENDE, Fernando. "Ausências na Comunicação Social e no Jornalismo: a lógica da rua”. Oficina do CES. Coimbra: Centro de Estudos Sociais, 2003 (www.ces.uc.pt / Oficina n.197).

doutoramento).

“o olhar às avessas - a lógica do texto jornalístico". São Paulo: ECA/USP, 2002 (tese de

SANTOS, Boaventura de Sousa. "Os processos da globalização". In: SANTOS (org.) Globalização: fatalidade ou utopia? Porto: Afrontamento, 2001, p.31-109.

TUCHMAN, G. "A objectividade como ritual estratégico: uma análise das noções de objectividade dos jornalistas”. In: TRAQUINA, N. (org.). (1999) Jornalismo: questões, teorias e “estórias” . Lisboa: Vega.

\section{Notas:}

(1) Aqui, por razões de espaço, os estudos de paradigma positivista estão sendo tratados de forma generalista. O pensamento sobre os estudos do jornalismo, na sua perspectiva hegemônica, encontra-se melhor desenvolvido em RESENDE (2002).

(2) RAMOS (2005) identifica três campos éticos distintos no que se refere à representação do outro na produção de documentários. Nossa reflexão quer levar adiante a problemática levantada por este autor, discutindo a mesma questão na perspectiva da produção chamada "jornalística". 
(3) Em http://www1.folha.uol.com.br/folha/ilustrada/ult90u59234.shtml (acesso 23/05/2008).

(4) Flusser (2002) divide as informações contidas nos discursos em indicativas, imperativas e optativas. A primeira delas, para o autor, é a classe das chamadas "informações jornalísticas" e tem a verdade como o seu ideal clássico. Também parece interessante notar que tal classificação de informações nos remete diretamente ao que diz Foucault (1996) em relação aos procedimentos de exclusão que são internos ao discurso; este é o caso dos produtos da mídia especificamente tratados neste ensaio.

(5) Flusser (2002) ancora-se nas nossas condições históricas e culturais para fazer uma interessante reflexão em torno da presença das imagens no mundo contemporâneo. Para este autor, as "imagens tradicionais" - os desenhos rupestres - serviam para imaginar o mundo, e quando essas imagens entram em crise os textos escritos, fundadores da história cronológica moderna, chegam para cumprir a função de explicar as imagens que imaginam o mundo.

(6) Para Castro-Gómez (s/d:14), “a ampliação do conceito de ideologia (...) pode ser muito valiosa para entender como as imagens, figuras e narrativas simbólicas (...) constroem representações que servem para reforçar o domínio de uns grupos sobre os outros. Estas representações ideológicas não são (...) unitárias, como pensava o primeiro Althusser. Através dos meios constroem-se não somente as grandes ideologias econômicas e políticas, mas também ideologias de gênero, raça, sexualidade e posição social que não são necessariamente reduzíveis umas às outras". Esta reflexão pode ser somada à de APPADURAI (2003), que vê as imagens e textos como representações sociais fundamentais para a construção de sentido no mundo contemporâneo.

\section{Mini Currículo :}

Professor do curso de Estudos de Mídia e do Programa de Pós-Graduação em Comunicação, do Departamento de Estudos Culturais e Mídia, da Universidade Federal Fluminense (UFF). Autor do livro Textuações - ficção e fato no Novo Jornalismo de Tom Wolfe (Annablume/Fapesp, 2002). 